\title{
Application of Information Communication Measurement Based on South Net Reference Station Technology in Power Data Acquisition
}

\author{
Zhenjiang Lei, Kun Su, Chunsheng Yan, Xuming Lv and Yongjian Zheng \\ State Grid Liaoning Electric Power Co., Ltd. shengyang 110006
}

\begin{abstract}
In the process of daily electricity production, the data of geo-information resources of power grid equipment is basically collected by the field site staff. Currently, the main problem is how to use advanced information communication measurement technology to support and improve the accuracy and efficiency of the geo-information resources of power grid equipment. If the data acquisition of the electrical equipment using the traditional real-time kinematic (RTK) technology, the longest distance of the data acquisition just have $10 \mathrm{~km}$ and each time of the data acquisition needs to point correction, calibration accuracy exists certain fluctuation. So, South Net Reference Station(NRS) technology is proposed to solve the practical problems of low accuracy and low efficiency of geographic information collection.
\end{abstract}

Keywords-South Net Reference Station(NRS) technology; power equipment geographic information data; real-time dynamic difference; GPS

\section{INTRODUCTION}

The development of information and communication technology has made the rapid development of geographic information measurement technology, and the development of satellite navigation technology has also developed by leaps and bounds. From the analysis of the overall structure of GIS system construction, it is divided into database construction and application platform construction. The database construction accounts for $50-80 \%$ of the system construction. The data mainly includes basic geospatial data, grid resource spatial data and grid resource attributes data and so on. Basic geospatial data is mainly for the operation of the grid to provide geospatial reference, mainly as a background map to use, the database construction data collection and storage is the entire project cost of energy, the most time, due to grid resources, spatial data collection of large, total station and other traditional data collection is unable to complete this task, must use GPS measurement means. Beidou satellite navigation system is China's implementation of the independent development, independent operation of the global navigation satellite system. The use of Beidou satellite network continuous reference station system can provide users with precise geographical positioning function, measurement accuracy to achieve high accuracy standards. In this paper, the application of State Grid Liaoning Electric Power Co., Ltd(The following is called Liaoning Company) based on Beidou satellite network continuous reference station system in the camping data collection work, through information technology to support the power equipment geographic information data high precision measurement applications are described.

\section{THE INTRODUCTION OF CONTINUOUSLY OPERATING REFERENCE STATIONS}

At present, the use of Continuously Operating Reference Stations(abbreviated as CORS) has become one of the hot spots of GPS applications. CORS system is the satellite positioning technology, information network technology, information and communication technology and other high-tech multi-directional, deep crystallization of the product.

CORS system develops hardware, software and maintenance management system independently in China, greatly improving the traditional satellite navigation system positioning accuracy. CORS system through the establishment of high-precision navigation and positioning network to support the measurement area of high-precision geographic information positioning and external service needs, customers can provide high-precision continuous dynamic three-dimensional spatial coordinate data resources.

In terms of security, as our own autonomous satellite navigation system, Beidou satellite system can be used in the replacement of foreign systems, to avoid the existence of foreign satellite navigation system, the underlying application of security risks.

In the user application, the Beidou system has a unique communication function, can provide more services than the GPS system.

In terms of technology, compared with the GPS system, can further improve the DOP (precision and strength) relative error value, reduce the impact of signal interference, weaken the interference of multipath effects. Which is beneficial to improve the accuracy of UTC world standard time. At the same time, control shorten the first positioning time, stabilize the carrier phase ambiguity and facilitate the application of abnormal error diagnosis.

\section{The CONSTITUTION OF SOUTH NET REFERENCE STATION(NRS) TECHNOLOGY}

\section{A. The Hardware of South Net Reference Station(NRS)}

Technology

NRS hardware architecture system of Liaoning company using China's Beidou satellite positioning and navigation system platform system, through the application of domestic independent intellectual property rights dedicated CORS reference station, to achieve the scope of Liaoning Province, power grid equipment through the precise geographical 
coordinates of information collection and positioning function. The NRS hardware architecture system of Liaoning company includes: CORS reference station, base station host and data communication link part.

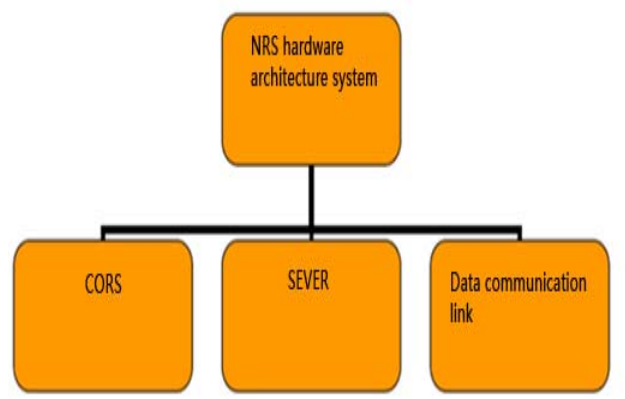

FIGURE I. NRS HARDWARE ARCHITECTURE SYSTEM

According to the technical requirements of the continuous reference station system of the Beidou satellite network, the scientific calculation and economic benefit analysis are carried out. Combined with the actual situation of the Liaoning electric power production, the perfect part of the compass station of the Beidou satellite network is established. According to the distribution of pre-distribution analysis, in the province of Liaoning through the layout of the 15 reference stations, to meet the national network of Liaoning company management within the scope of major cities and regional electrical equipment, geographical coordinates of information collection and positioning applications to ensure that the measurement accuracy to meet the sub-level positioning requirements The The establishment of the 15 reference stations average distance of about $100 \mathrm{~km}$, can be completely covered in the main city of Liaoning Province and its surrounding areas.

Liaoning Electric Beidou satellite network continuous reference station system station site is reasonable, the site away from the electromagnetic interference area, the surrounding distance without tall buildings, trees, water, beaches and eclectic zone. All the reference stations are set in the Liaoning company around the city branch management within the fixed building, 15 consecutive reference station equipment completely run by the Liaoning company unified management.

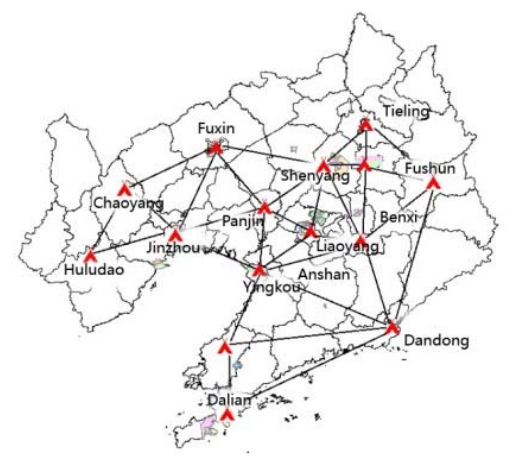

FIGURE II. LOCATION DESIGN OF CORS BASE

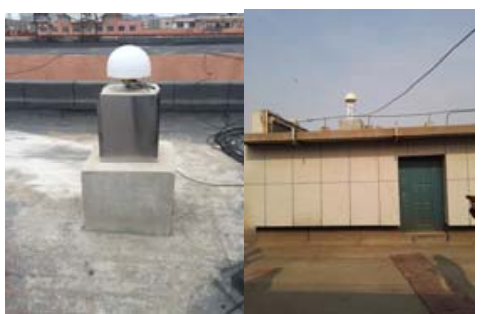

FIGURE III. STATION ANTENNA OF CORS BASE

Liaoning company made Beidou satellite network continuous reference station system host and data communication link is to achieve the reference station data and data processing center transmission and communication carrier, the reference station and the system control center and the flow station and the system between the server and so on Data transmission is carried out through the network, so the formation of a control system connected to the control center and the reference station of the wide area network, the user collected in the collection process to the data processing center for processing and analysis, and after the solution Of the data transmission to the user terminal.

\section{B. The Software of South Net Reference Station(NRS) Technology}

The system includes: Base Station Management System (NRS Center), Data Processing Center (NRS Net) and User Management System (NRS Server). The basic core theory of NRS technology, derived from VRS technology, it has all the characteristics of VRS technology, while absorbing some of the advantages of FKP, the main auxiliary station technology.

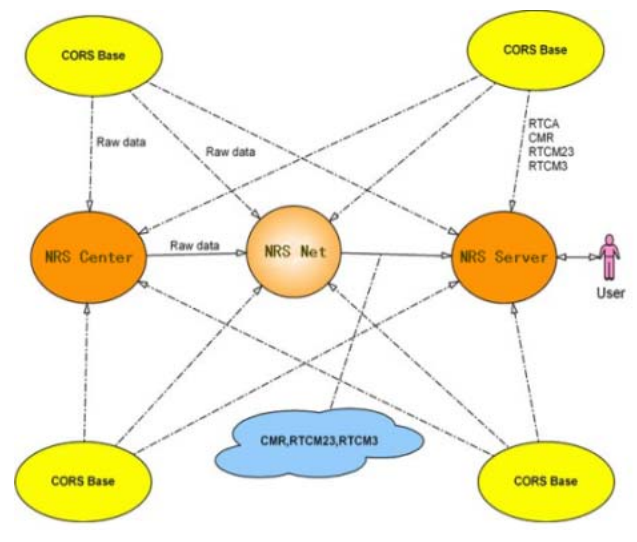

FIGURE IV.THE SOFTWARE OF NRS

\section{1) NRS Center}

The base station management system is one of the components of the network continuous reference station software system. Its function is to save the collected raw data according to the set sampling interval, transfer the original data to the network or the serial port, and provide the original application for the system. Of the observed data. The base station management system provides the original data for the operation of the network continuous reference station, which is an indispensable part of the network continuous reference station system. 


\section{2) NRS Net}

The data processing center is the core component of the network continuous reference station software system, completes the whole network solution and the enhancement of the virtual reference station data generation. The data processing center mainly completes the three-step process of network RTK data processing, that is, the calculation of the ambiguity of the whole network, the establishment of the error model and the transmission of the differential correction data. Through the use of network continuous reference station differential technology, the use of the entire network of reference station correction data, to amend the user terminal near the three reference station data. And uses the corrected three reference station data to virtualize an enhanced reference station near the user terminal to provide the network differential application service for the user terminal.

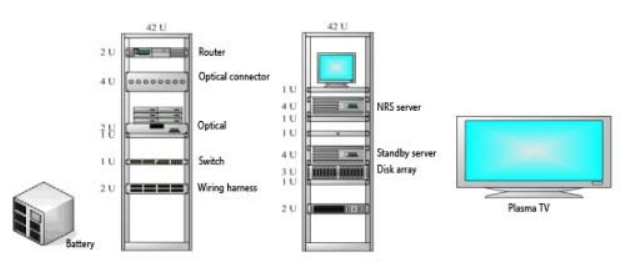

FIGURE V. SEVER STRUCTURE

\section{3) NRS Server}

The user management system completes the distribution of the differential data, and the user management is the user-oriented part of the network continuous reference station software system. The user terminal is connected to the user management system through the NTrip protocol and sends its own rough coordinates to the user management system. The user management system sends the rough coordinates to the data processing center. The data processing center generates the corresponding differential correction number according to the approximate coordinates and the differential correction number is sent to the user management system, and then the user management system will then send the difference correction number with the NTrip protocol to the user terminal.

\section{KEY TECHNOLOGY OF NRS IN LIAONING COMPANY}

A. On the Basis of VRS Technology, Combined with the Advantages of Some FKP and MAX Technologies, VRS Is Optimized

VRS technology uses only the number of corrections for the three base stations around the rover, generates a virtual reference station using the corrections of the three base stations near the rover, and uses the virtual reference station in a similar way to the traditional RTK Sent to the rover. Although VRS can be compatible with traditional RTK, but did not use the other base station correction information. The FKP and MAX techniques use the corrections of a series of (or even the entire network) stations around the rover to generate a correction model that sends the model parameters and the observations of the master station to the rover. Although FKP and MAX use more base station corrections, the amount of data sent is large and can not be compatible with traditional RTK.
NRS combines the benefits of VRS, FKP and MAX to provide a more reliable and efficient network CORS service. NRS has adopted a correction method similar to VRS, that is, the selection of three base stations near the mobile station, the use of these three stations to correct the number of information in the vicinity of the mobile station to generate a virtual base station. But unlike VRS, NRS technology uses some or all of the base stations in the network to optimize the number of corrections in the vicinity of the rover, making the corrections more accurate. A virtual reference station generated using an optimized number of corrections is called an enhanced virtual reference station. The enhanced virtual reference station provides a more reliable, more accurate network CORS service.

\section{B. NRS Uses DEEP-NRS Technology, Greatly Improving the Availability of CORS Network}

NRS-specific Deep-NRS technology is based on the VRS network program to do a certain degree of adjustment and strengthening. When the number of base stations in the CORS network exceeds four, the role of Deep-NRS technology is reflected. VRS only chooses the nearest three base stations from the mobile station to construct the triangles for the area, while the Deep-NRS technology combines all eligible triangles (conditions such as: baseline length $\leqslant 80 \mathrm{KM}$, triangular minimum angle greater than 30 degrees, etc.) are built, so in many cases, the same area may have redundant triangles can provide services, and NRS will automatically according to the baseline edge distance, triangulation lock the same satellite number, the base station network transmission data quality Etc. to sort the available triangles to select the optimal triangle to serve the mobile station. When the optimal triangle is not available, another triangular network can fill up in time, which makes CORS network service availability and stability greatly improved, the accuracy and efficiency of the project has also been guaranteed.

\section{According to the Mobile Terminal in the Base Station Network Location Automatically Select the Job Mode, to Ensure That the Mobile Side to Obtain the Best Accuracy}

At the same time, in order to ensure the accuracy of the system and improve the system availability, the NRS software can automatically provide the virtual reference station, multi-base station and single base station service for the mobile users according to the location of the mobile terminal in the base station network. You can get the best positioning accuracy. For example, it can be set in the system, and the distance from the base station (A base station) is within $5 \mathrm{Km}$. When the mobile station is connected to the NRS system, the single base station differential data provided by the A base station will be obtained, Better differential accuracy than network reference station.

\section{Parameter Encryption and Broadcasting Technology, User-friendly at the Same Time, to Ensure the Safety of Station Parameters}

The system has reliable, easy-to-use and practicable security measures for the parameters and data of the coordinate transformation model and the geoid model. When providing the location service, NRS can directly publish the local 
coordinate correction parameters or the integrated coordinate transformation model, and the geoid model, and the elevation anomaly parameters, which are encrypted in the encryption mode of the virtual reference station. The machine realizes the local coordinates and elevation of the anchor point by accepting the difference correction number. That is, the mobile end user can realize the conversion between coordinate systems without knowing the local coordinate conversion parameters and the elevation anomaly parameters. Both to facilitate the user's work, but also effectively solve the problem of confidentiality of the results of the parameters. Encryption measures for various types of mobile station equipment development, can be applied to the current market mainstream brands of RTK.

\section{THE SYSTEM APPLICATION OF NRS IN LIAONING COMPANY}

The country vigorously promote the development of the global energy Internet and smart grid, in the power production camp with the work, the Liaoning company power equipment geographic information data measurement work to basic information communication measurement technology as the support, through the application of Liaoning company Beidou satellite network continuous reference Station system to obtain high positioning accuracy, good stability of the electrical equipment, geographic information data, to achieve power distribution operations through the important information support.

\section{A. Functional Application}

1) Establishment of Geographic Coordinate Benchmark for Application of Liaoning Regional Power Grid

Beidou satellite network continuous reference station system to provide users with a stable and unified coordinate system to improve the accuracy of measurement data to ensure the consistency of measurement expertise, effectively reduce the chance of systematic errors, improve the efficiency of measurement work. The electrical equipment geographic information measurement data unified in a coordinate system framework, to facilitate the various departments of the data exchange, sharing, seamless convergence.

The establishment of this system, established the CGCS2000 reference framework, to ensure that the provinces of the data space reference system of consistency, to avoid their respective cities around the government, data chaos phenomenon. In addition, in this system, the industry personnel do not need to set up a conventional reference station can operate, not only reduces the workload of the field, but also greatly reduces the professional and technical difficulties, making the internal power of non-professionals easy to master, A lot of manpower and material resources, effective guarantee of power grid GIS data collection progress, quality, in the construction of power grid GIS platform has played a huge role.

Therefore, the establishment of CORS system has the foundation support function to the construction of GIS platform, which is of great significance to the data quality, schedule and maintenance of data collection.
2) Improving the Application of Geographic Information Application in Liaoning Regional Power Grid

The traditional power equipment measurement method is mainly used GPS-RTK, total station and other instruments, measurement efficiency is low, and because of environmental, terrain and other factors, GPS-RTK base station signal transmission is greatly affected, affecting the measurement work progress. The introduction of Beidou satellite network continuous reference station system measurement method, can effectively solve the above problems in the measurement, improve the measurement accuracy and efficiency, get a good overall benefits.

Compass satellite network continuous reference station system has: all-weather in the measurement area to start work, and not covered by the base station coverage. Do not need to look at the environment, reducing the construction, woods, crops and other effects on power measurement. High precision measurement time is short, can provide real-time service, easy to operate low labor intensity.

\section{3) To provide Liaoning Regional Power Grid Application of Different Precision Needs Data}

In Liaoning regional power application, through the use of Beidou satellite network continuous reference station system, not only to meet the real-time requirements of Liaoning users, but also to provide users with dynamic difference method, dynamic processing, static differential method and global differential positioning Systems and other technical processing of the data, and to ensure that the processing data with high accuracy.

At the same time, users can also achieve the difference between the different accuracy and considerations, to provide users with different levels of data, including meters, sub-meter level measurement accuracy level.

\section{B. Safety and Efficiency Applications}

State Grid Enterprise Electric Power Equipment Geographic information resources data related to national strategic security, social basic service security. Power equipment Geographic information resources Data security, confidentiality and reliability are the core concerns of power measurement.

China's Beidou satellite system since put into operation, has been working stable and reliable, has been commercial application conditions have been very mature. In the aviation, aerospace, navigation, railways, transportation, marine and other fields have a successful application paradigm. The most important aspect, the Beidou satellite system is developed by our country, not subject to the control and restrictions of other countries, reliability and security of a higher guarantee. US GPS currently eliminates SA's choice of availability availability, but can still be mixed with interference signals at any time to reduce positioning accuracy, and may even turn off usage rights for users in other countries. Therefore, the use of domestic Beidou satellite system platform for the development of the relevant application system, in the protection of China's basic energy grid equipment, geographic information applications, security applications have the initiative. 
The traditional power equipment application of geographic information measurement work, take more than the total station and other measurement methods, take a long time, the workload is large, and the impact of measurement work more factors, the existence of low efficiency of the actual situation. By applying the Beidou satellite network continuous reference station system to the electric power measurement work, it can effectively improve the measurement precision, reduce the workload and improve the precision measurement efficiency.

\section{Business Applications}

In the Liaoning company marketing business, distribution network business, scheduling business (camp with tune) through the work, in the face of various types of power equipment assets stock is huge, incremental changes quickly, data collection tasks and other characteristics, through the application of Beidou satellite network continuous The reference station system provides stable, reliable and continuous positioning and measurement services for grid geographic data collection. In improving the business application of mapping speed and efficiency, but also greatly reduces the relevant business applications mapping labor intensity and cost. To further realize the structured management and graphical display of power grid resources, and to improve the accuracy of providing high-precision positioning and measurement services for grid space information in line with SG186 engineering specification for all kinds of business applications, and to collect precision for geophysical data And quality provides further protection.

Liaoning companies in the power transmission, substation, power distribution, electricity, public facilities and other business, relying on the Beidou satellite network continuous reference station system, can meet the following business resources grid equipment spatial information collection accuracy and efficiency requirements.

\section{CONCLUDING REMARKS}

This paper focuses on the new generation of information communication support technology - Beidou satellite network continuous reference station information communication measurement technology, to overcome the traditional RTK technology cumbersome operation steps, reduce the work intensity, long distance measurement provides a consistent signal source for the power grid equipment Resources provide a unified spatial geographic information coordinate system.

With the smart grid, three sets of five major construction in depth, the urgent need for a set of reference station system to meet the provinces and cities of the company's full-service power grid equipment resources, high-precision measurement needs. At the same time, in the work of the camp through the work, the application of continuous high-precision positioning measurement data at the same time, greatly improve the power equipment, geographic information resources, data collection accuracy and efficiency, and constantly enhance the power of geographic information data acquisition support The

\section{REFERENCES}

[1] Beijing CORS network base station data processing and precision analysis [J]. Kun ZHENG, Xurong DONG, Lianjun DAI, Xi ZHANG, Zhifeng NIE. Global Positioning System. 2010 (05)
[2] CORS user management system research and development [J]. Xinxiu ZHAO, Jiexian WANG. Engineering Survey. 2010 (09)

[3] Gansu held CORS construction and application site will be [N]. Cao RUI , Li Chen WANG. China Surveying and Mapping. 2015-08-11 (003)

[4] Shanghai Beidou CORS application demonstration project operation [N]. Qingying ZHANG. China Surveying and Mapping. 2013-10-18 (002)

[5] CORS station system positioning accuracy analysis and detection methods [D].Sheng CHEN. Kunming University of Science and Technology 2011

[6] virtual reference station (VRS) technology and its accuracy assessment [D]. Yang YANG. Southwest Jiaotong University 2007

[7] satellite positioning continuous operation reference network system architecture and software system design [D]. Jian LI. People's Liberation Army Information Engineering University 2007

[8] the first domestic CORS monograph published [N]. Junjie FAN, Bailiang LI. China Surveying and Mapping. 2009-02-20 (003)

[9] CORS evolution process [N]. Yongsheng LIAO, Changzeng TANG, Bailiang LI. China Surveying and Mapping. 2009-01-23 (003)

[10] The main and auxiliary station technology positioning principle and algorithm research [D]. Yuying LIN. People's Liberation Army Information Engineering University 2010

[11] Beidou satellite communications in the field of civilian technology applications [J]. Jianfeng ZUO. China's new communications. 2013 (18)

[12] CORS - the only way to modernize urban management [N]. Jiangsu Science and Technology News. 2007-04-09 (A11)

[13] Guangxi Beibu Gulf Economic Zone CORS system put into trial operation [N]. Guangsheng TANG, Shaoning WEI. Guangxi Daily. 2007-09-07 (002)

[14] Hunan CORS built and passed the acceptance [N]. Houchang LIU. China Surveying and Mapping. 2011-12-09 (002)

[15] Beidou satellite in the application of electric power emergency communication [J]. Zhenjie ZHANG, Rui GONG, Wanyi FENG. China New Communications. 2015 (23)

[16] Based on the Beidou satellite system generator development phase monitoring system [J]. Yanfang WEI, Zhinong WEI, Guoqiang SUN, Peng CHEN. East China Power. 2011 (10)

[17] Broadcom chip supports China's Beidou satellite system [J]. Digital Communications World. 2013 (12)

[18] Based on the Beidou satellite navigation search and rescue system principle and configuration [J] .Youjun PANG. Avionics. 2013 (04)

[19] The Beidou satellite will be "as much as" for precision agriculture. [J]. Seed World. 2013 (07)

[20] National Beidou satellite navigation product testing organizations set up [J]. Space Electronics. 2013 (03)

[21] Nanjing High-tech Zone: Beidou industry application achievements Wisdom life [J]. Zhu WEN. Digital communication world. 2013 (S2) 